\title{
Thermophotovoltaic energy in space applications: Review and future potential
}

\author{
A. Datas , A. Martí
}

\begin{abstract}
A B S T R A C T
This article reviews the state of the art and historical development of thermophotovoltaic (TPV) energy conversion along with that of the main competing technologies, i.e. Stirling, Brayton, thermoelectrics, and thermionics, in the field of space power generation. Main advantages of TPV are the high efficiency, the absence of moving parts, and the fact that it directly generates DC power. The main drawbacks are the unproven reliability and the low rejection temperature, which makes necessary the use of relatively large radiators. This limits the usefulness of TPV to small/medium power applications $\left(100 \mathrm{~W}_{\mathrm{e}}\right.$-class) that includes radioisotope (RTPV) and small solar thermal (STPV) generators. In this article, next generation TPV concepts are also revisited in order to explore their potential in future space power applications. Among them, multiband TPV cells are found to be the most promising in the short term because of their higher conversion efficiencies at lower emitter temperatures; thus significantly reducing the amount of rejected heat and the required radiator mass.
\end{abstract}

\section{Introduction}

A number of technological options exist for power generation in space, which are selected depending on the mission duration and the electric power requirements. For very short missions, chemical energy is usually employed in the form of non-rechargeable batteries, fuel cells and combustion turbo-alternators. For larger missions, solar photovoltaics (PV) with rechargeable batteries are the most common choice. Solar PV is mostly employed for near-Sun (Earth orbit or closer) space missions, enabling power levels of several kWs and mission duration of several years [1]. An eventual alternative to solar PV are solar thermal generators, which enable very high energetically dense thermal storage. These systems have been explored both theoretically and experimentally, but no flight experiments have been carried out yet. Nuclear power systems (NPS) [2] have been used for deep space missions, where the solar intensity is too low, and for planetary applications where the day/night cycling and settling of dust negatively impacts on solar PV performance. Among the nuclear options, radioisotope power systems (RPS), typically using Pu-238 heating source [3-5], have been extensively used for $\sim 100 \mathrm{~W}_{\mathrm{e}}$ nominal power applications. Fission power systems (FPS) that use nuclear reactor have been developed for medium/high power applications, from $\sim 1 \mathrm{~kW}$ to several 10's or 100 's of $\mathrm{kW}_{\mathrm{e}}$, and they are currently under consideration for power generation in future planetary settlement missions.

A number of technological options exist to convert primary energy into electricity. A few of them enable a direct conversion process (e.g. PV and fuel cells), but the majority require the intermediate generation of heat, which is subsequently converted into electricity by a heat engine. Thus, many kinds of heat engines have been developed within the frame of international space power R \& D programs. Among them, only those based on solid state devices (thermoelectrics and thermionics) have been flown in space, while the dynamic systems (Rankine, Stirling and Brayton) are still under development to demonstrate high levels of reliability.

Thermophotovoltaics (TPV) [6-8] is a high efficient solid-state alternative to thermoelectric and thermionic converters (Fig. 1). In TPV, electricity is produced directly from radiant heat by means of infrared sensitive PV cells, named TPV cells. Advantages of TPV with respect to competitors are the high efficiency ( $25 \%$ in current state of the art devices [9] and potential to reach $\sim 40 \%$ [10]), the low weight, the independence of pressure and gravitational force, the absence of moving parts and the fact that it directly produces DC power. The main concern of TPV is the low rejection (TPV cell) temperature, which implies a large radiator area and limits the usefulness of TPV to relatively small power outputs, typically below $1 \mathrm{~kW}$ [11] (Fig. 2). This matches solar powered systems, radioisotope $\left(\sim 100 \mathrm{~W}_{\mathrm{e}}\right)$ [12-15], and perhaps small (kilowatt-class) nuclear reactors [16,17]. Other important concern of TPV is the unproven reliability for long-term missions, especially concerning the possible contamination of the TPV optical elements by the evaporation of materials at very high temperatures. 


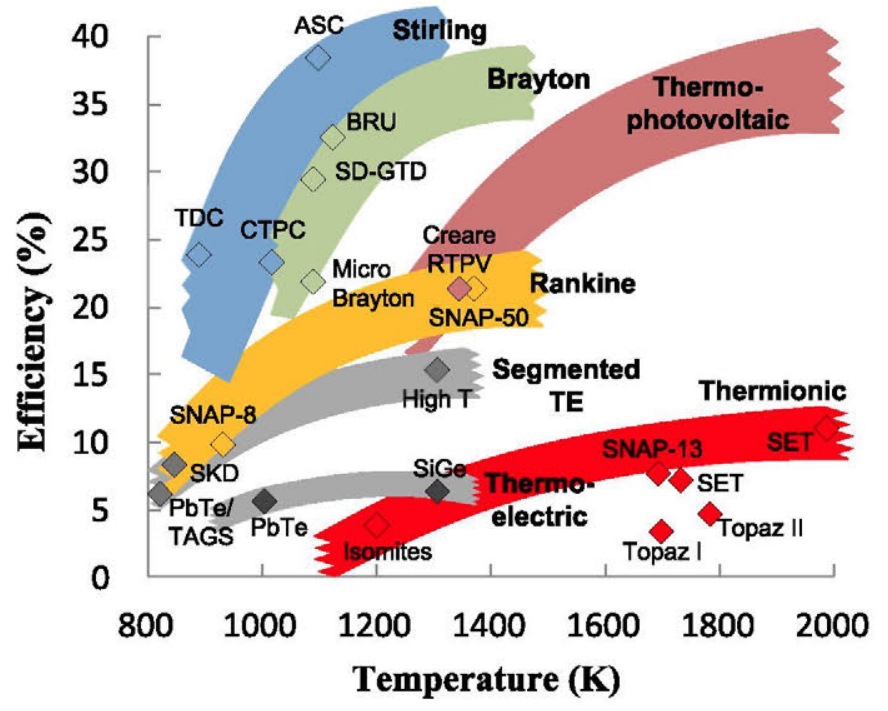

Fig. 1. Heat-to-power conversion efficiency as a function of hot-side temperature for several technologies.

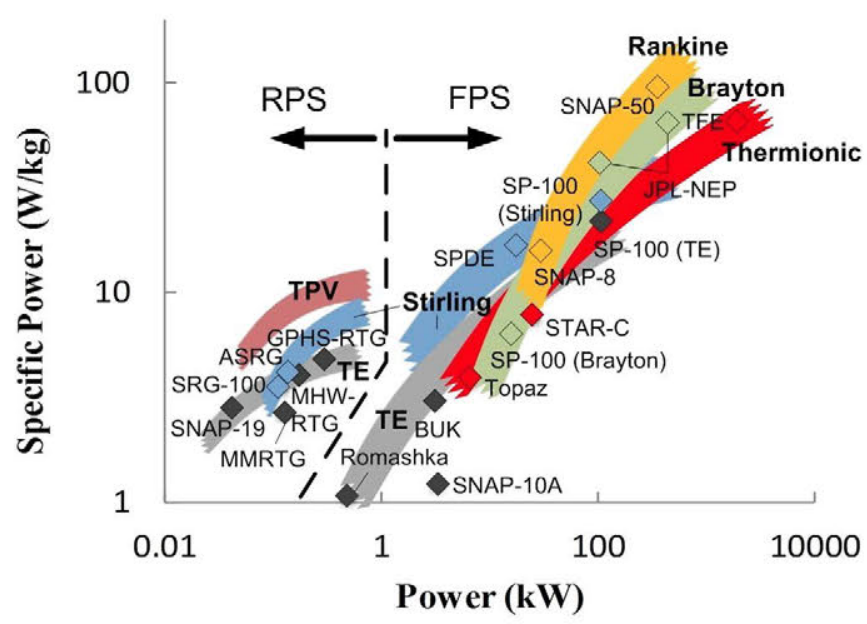

Fig. 2. Specific Power of nuclear power systems as a function of output electrical power.

(Figs. 3 and 4).

This article reviews the historical developments of TPV and that of the main competing technologies in the field of space power generation. The final goal is to provide an overview of the current state of the art, and of the novel TPV concepts that may determine its future potential. Among the so-called novel concepts, the use of multiband TPV cells seems to be the most feasible option in the short term. Thus, we have studied this case in greater detail, using a model that has been adapted to this study from previous work [10] to determine the improvement potential of substituting state of the art $\sim 0.6 \mathrm{eV}$ InGaAs single junction TPV cells by the next generation dual junction devices.

\section{Review of heat-to-power conversion in space}

Heat-to-power energy conversion in space has had two main applications: nuclear and solar-thermal generation, although only nuclear systems have been flown in space. Thermoelectrics is the most deployed technology in small RPS and thermionics were used in the earliest FPS that were flown into space by the former Soviet Union. Currently, the higher efficient dynamic power generation systems (mostly Rankine, Brayton and Stirling) are being considered for future replacement of solid state converters. The use of higher efficient generators enables a significant reduction of the nuclear fuel for providing the same amount of power (e.g. for an efficiency of $25 \%$, it

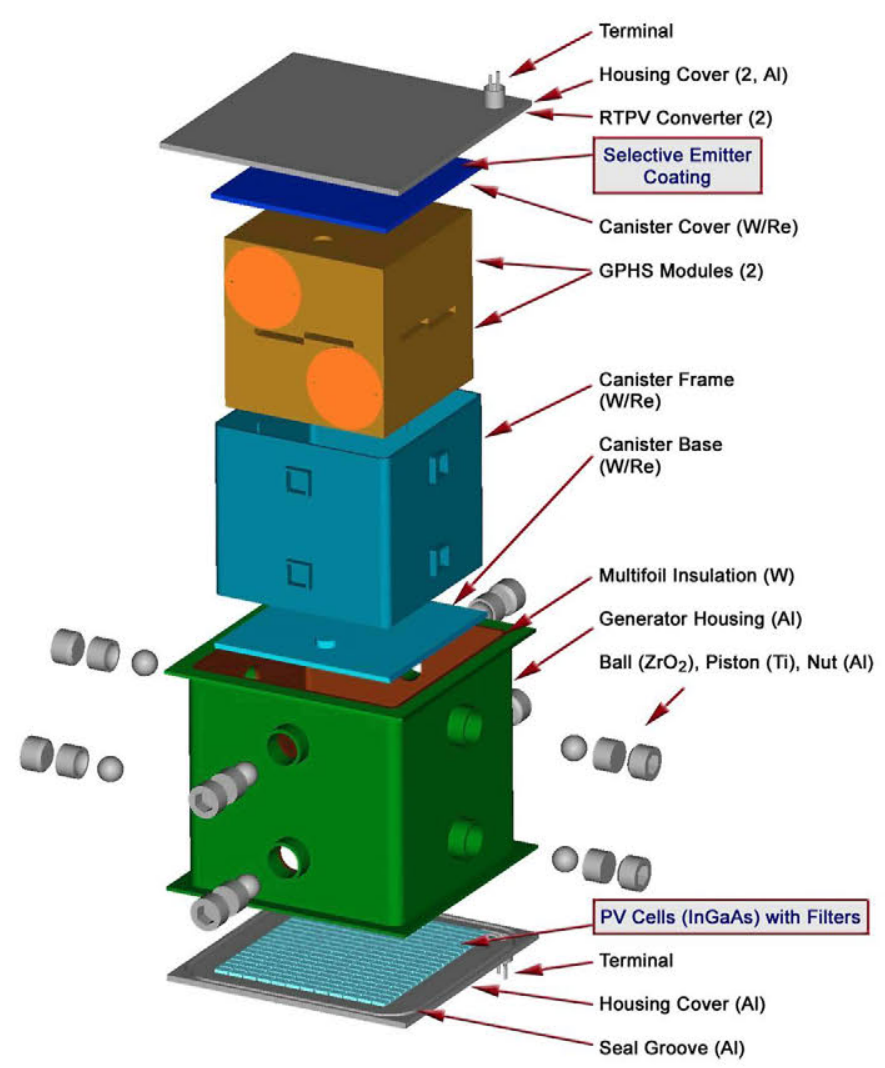

Fig. 3. RTPV design proposed in [34]. Reproduced from reference [37].

would be needed one fourth of the nuclear fuel than that of required for $6 \%$ efficient thermoelectrics). This is very relevant not only for increasing the specific power, but also for mitigating the serious issues of producing high amounts of extremely scarce nuclear fuels, such as Pu-238.

Fig. 1 shows the conversion efficiency as a function of hot-side temperature for the different heat-to-power technologies. Fig. 2 shows the (in some cases projected) specific power of several NPS (both RPS and FPS) that utilize different heat conversion technologies. In this section we briefly describe the technological developments carried out for each of these heat-to-power conversion technologies. TPV development will be described in Section 3 .

\subsection{Thermoelectrics}

Thermoelectric converters produce power through the Seebeck effect, which takes place when the joint between two dissimilar materials, i.e. metals or semiconductors, is subjected to a temperature difference [18]. Thermoelectric converters are robust and reliable, but they have low conversion efficiency, typically of $\sim 6 \%$, which translate into a low specific power of $\sim 5 \mathrm{~W} / \mathrm{kg}$ or below. Thermoelectric converters have been used extensively in space applications since 1961, with more than 60 space missions launched (27 from U.S. and 33 from the former Soviet Union) [19]. Most of U.S. missions used radioisotope thermoelectric generators (RTG) with low electric power levels (less than $\sim 300 \mathrm{~W}_{\mathrm{e}}$ ) for earth-orbiting and planet exploration missions. On the contrary, the former Soviet Union mostly focused on FPS, with higher electric power outputs, in the range of $500-3000 \mathrm{~W}_{\mathrm{e}}$, which were used mostly for earth observation missions.

\subsubsection{Radioisotope Thermoelectric Generators (RTG)}

First RTG units were developed within the U.S. SNAP program and were launched in missions from 1961 to 1975 to produce typically from $\sim 3 \mathrm{~W}_{\mathrm{e}}$ in the early earth-orbiting designs to $75 \mathrm{~W}_{\mathrm{e}}$ in the later lunar surface missions $[4,18]$. These designs used $\mathrm{Pu}-238$ fuel and $\sim 6 \%$ 


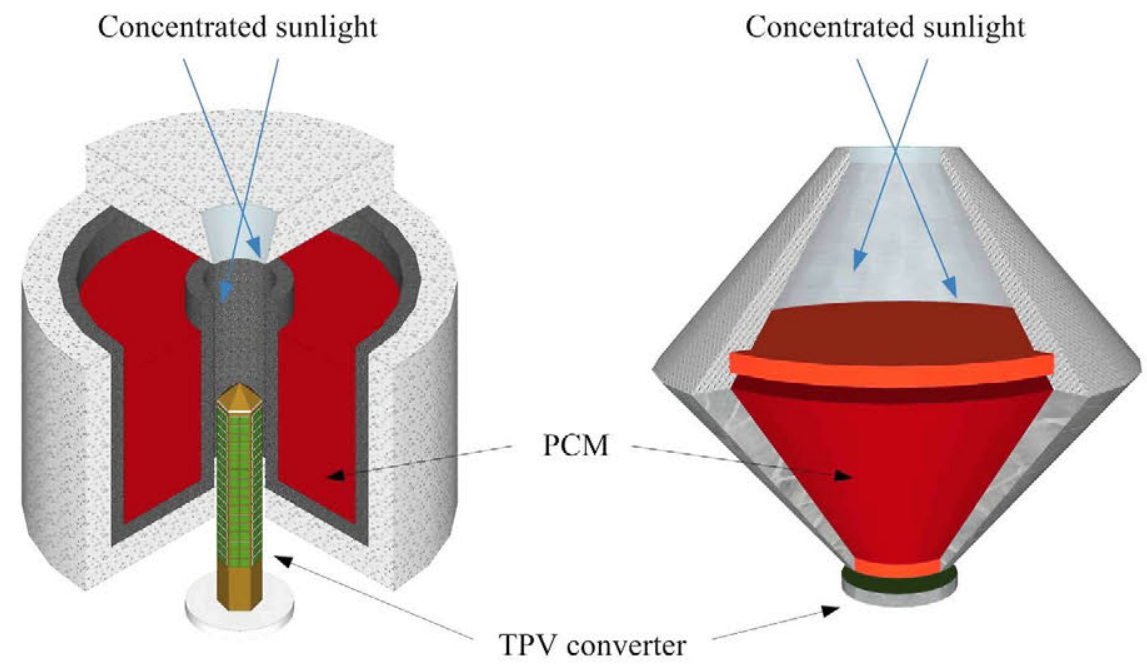

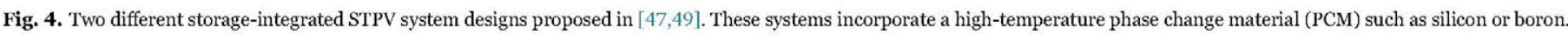

Table 1

Comparison of different RPS performance (those marked with * are projected values). Data for GPHS-RTG, MM RTG, SRG110 and ASRG* are taken from [19,39]. Data for ASRG is taken from [32], and RTPV* is taken from [12]. Other small thermoelectric generators not shown in this table are the MHW-RTG $\left(4.2 \mathrm{~W}_{\mathrm{e}} / \mathrm{kg}\right)$, the SNAP-19 $\left(3 \mathrm{~W}_{\mathrm{e}} /\right.$ $\mathrm{kg})$ and SNAP-27 $\left(3.7 \mathrm{~W}_{\mathrm{e}} / \mathrm{kg}\right)[19]$.

\begin{tabular}{|c|c|c|c|c|c|c|}
\hline & GPHS-RTG & MM RTG & SRG110 & ASRG & ASRG $^{*}$ & $\mathrm{RTPV}^{*}$ \\
\hline $\begin{array}{l}\text { BOM net electric } \\
\text { power }\end{array}$ & 285 & 125 & 116 & 130 & 160 & 100 \\
\hline $\begin{array}{l}\text { Hot-end } \\
\text { temperature, } \\
{ }^{\circ} \mathrm{C}\end{array}$ & 1000 & 538 & 650 & - & 850 & 1077 \\
\hline $\begin{array}{l}\text { Cold-end } \\
\text { temperature, } \\
{ }^{\circ} \mathrm{C}\end{array}$ & 300 & 210 & 80 & - & 80 & $\sim 50$ \\
\hline \#GPHS modules & 18 & 8 & 2 & 2 & 2 & 2 \\
\hline $\begin{array}{l}\text { BOM heat input, } \\
\text { Wt }\end{array}$ & 4500 & 2000 & 500 & 500 & 500 & 500 \\
\hline RPS efficiency & 6.3 & 6.3 & 23.2 & 26 & $\sim 32$ & 20 \\
\hline $\begin{array}{l}\text { Radiator area } \mathrm{m}^{2} / \\
\quad \mathrm{kWe}\end{array}$ & $\sim 3.6$ & $\sim 7.4$ & $\sim 6.2$ & - & $\sim 4.0$ & $\sim 10$ \\
\hline $\begin{array}{l}\text { GPHS modules, } \\
\quad \mathrm{kg}\end{array}$ & 25.7 & 12.9 & 3.2 & 3.2 & 3.2 & 3.2 \\
\hline Total mass, kg & 56.0 & 44.2 & 32.5 & 32 & $\sim 19$ & - \\
\hline $\begin{array}{l}\text { Specific power, } \\
\mathrm{W}_{e} / \mathrm{kg}\end{array}$ & 5.1 & 2.8 & 3.6 & 4.1 & $>8$ & $>8$ \\
\hline
\end{tabular}

efficient PbTe thermoelectric converters. Later missions, such as Voyager 1 and 2 used multi-hundred Watt RTG (MHW-RTG) units containing SiGe converters to produce $\sim 160 \mathrm{~W}_{\mathrm{e}}$. Since 1989 , the predominant technology used general purpose heat source (GPHS) modules containing $\mathrm{Pu}-238$ fuel and SiGe thermoelectric converters. Each RTG contains 18 GPHS modules each having a specific power of $5.1 \mathrm{~W}_{\mathrm{e}} / \mathrm{kg}$ and an overall efficiency of $\sim 6 \%$, to generate a total of $\sim 290 \mathrm{~W}_{\mathrm{e}}$ (see Table 1). GPHS-RTG has been recently replaced by the so-called Multi-Mission RTG (MMRTG), designed to operate not only in vacuum, but also in oxidizing atmospheres. It comprises 8 GPHS modules to generate $125 \mathrm{~W}_{\mathrm{e}}$ and utilizes PbTe/TAGS thermoelectric converters. This system shows a specific power of $2.8 \mathrm{~W} / \mathrm{kg}$ and has been recently used in the Curiosity mission to Mars. A summary of the performance of the main RTGs is presented in Table 1.

Next generation developments on RTG at NASA include the development of enhanced MMRTG (eMMRTG) by substituting the current PbTe/TAGS devices by skutterudite (SKD) couples with enhanced conversion efficiency of up to $\sim 8 \%$, to reach specific powers beyond $3.6 \mathrm{~W} / \mathrm{kg}$ [20]. Also, high-power and high temperature advance radioisotope generators (ARTGs) using segmented thermoelectric couples are under consideration for developing $\sim 500 \mathrm{~W}$ class systems with efficiencies of $\sim 15 \%$ and specific power beyond $8 \mathrm{~W} / \mathrm{kg}$ [20].

\subsubsection{Fission Thermoelectric Generator (FTG)}

The SNAP-10A reactor has been the only U.S. fission reactor flown in space (in 1965) and used $\sim 1.5 \%$ efficient SiGe TE converters to generate more than $500 \mathrm{~W}_{\mathrm{e}}$ from a $43 \mathrm{~kW}_{\text {th }}$ reactor cooled with liquid $\mathrm{NaK}$ at averaged temperature of $\sim 600 \mathrm{~K}$ [18]. The former Soviet Union was the most active in developing fission reactors. One of them (Buk) powered at least 32 earth-observation missions [18] and used SiGe thermoelectric couples cooled by NaK loop at $\sim 600 \mathrm{~K}$ to produce $\sim 3 \mathrm{~kW}_{\mathrm{e}}$ from $100 \mathrm{~kW}_{\mathrm{th}}$. The other one (Romashka) was designed to produce $\sim 500 \mathrm{~W}_{\mathrm{e}}$ from a $28 \mathrm{~kW}_{\mathrm{th}}$, also using SiGe converters. To our knowledge, the latest experimental development of FTG was in 1983, during the U.S SP-100 program aimed at developing a $\sim 100 \mathrm{kWe}$ nuclear reactor using lithium coolant at averaged temperature of $1350-1375 \mathrm{~K}$ and using SiGe thermoelectric converters. Unfortunately, the program was canceled in 1993 without constructing any full SP-100 prototype.

\subsection{Thermionics}

Thermionic converters [21] are solid state devices in which a hot cathode emits electrons that are collected by a low work function anode. In this configuration, an electron flux is created from the cathode to the anode that can be delivered to an external load to produce power. The main benefits of thermionic converters are: high specific power, scalability to high power levels and modularity [22]. In the nuclear reactor applications, the main advantage of thermionics is its ability to operate inside the nuclear core, which eliminates the necessity of a heat transfer fluid, and reduces the overall weight and the temperature drop between the nuclear core and the converter. Besides, it has a high rejection temperature (several 100 's K) that allows using a small and low weight heat rejection radiator. This is particularly relevant for high power systems, for which the radiator mass is particularly important.

The former Soviet Union fabricated two nuclear reactors incorporating in-core thermionic converters, called TOPAZ and ENISEY (also known as TOPAZ II). TOPAZ was capable of generating $5 \mathrm{~kW}_{\mathrm{e}}$ from a $150 \mathrm{~kW}_{\text {th }}$ reactor operating at almost $1800 \mathrm{~K}$ core temperature, and reaching rejection temperatures of $880 \mathrm{~K}$. TOPAZ II demonstrated slightly higher efficiency and produced $5.5 \mathrm{~kW}_{\mathrm{e}}$ from a $\sim 130 \mathrm{~kW}_{\text {th }}$ reactor at similar rejection temperatures. These two systems were flown in 1987 during 6 and 12 months, respectively.

Early efforts in the U.S. involved both solar and nuclear in-core 
reactor systems. Solar thermionic development started within the Solar Energy technology (SET) program (1961-early 70's). During this program, more than 135 thermionic converters were tested at 1700 $2000 \mathrm{~K}$ emitter temperature range for more than $68,000 \mathrm{~h}$, demonstrating efficiencies between $7 \%$ and $11 \%$ and power densities in between 17 and $25 \mathrm{~W} / \mathrm{cm}^{2}$. A nuclear in-core thermionic generator was built at General Atomics (TRIGA) in between 1962 and 1973, and operated at core temperatures as high as $1900 \mathrm{~K}$ for more than $12,500 \mathrm{~h}$. Subsequently, as a part of the SP-100 program, the U.S started the Thermionic Fuel Element (TFE) verification program to investigate the lifetime issues of thermionic generators for very high power ( $>100 \mathrm{kWe}$ ) in-core nuclear reactors. This research validated the potential of this technology to meet mission life ranging from 3 to 7 years.

The U.S. also developed small thermionic converters for RPS applications, in the frame of the SNAP-3C1, 3D1 (vacuum thermionic converters) and SNAP-13 (cesium thermionic converter) programs [23]. The SNAP-13 system was built in 1966 and used ignited-mode cesium-filled approach to mitigate space charge issues [21]. This system demonstrated a conversion efficiency of $\sim 6.6 \%$ at a maximum temperature of $1680 \mathrm{~K}$. Milliwatt-class vacuum thermionic converters, so-called isomites, were developed by McDonnell Douglas in the early 70 's to produce $\sim 1 \mathrm{~W}$ with an overall efficiency of $\sim 4 \%$ at an emitter temperature of $1200 \mathrm{~K}$.

\subsection{Dynamic systems}

Dynamic systems perform heat-to-power conversion through an intermediate step in which a working fluid transfers the heat from the source to an engine that produces mechanical energy, which is subsequently converted to electricity. A number of dynamic systems exist depending on the particular thermodynamical cycle, being the most typical for space applications the Rankine, the Brayton and the Stirling.

Early developments on dynamic systems started in the 50's and focused on liquid metal cooled Rankine engines for FPS applications, under the SNAP-1, SNAP-2 and SNAP-8 programs (using mercury as working fluid) $[5,24]$ and SNAP-50/SPUR (using potassium as working fluid) [25]. Organic Rankine Cycle (ORC) were also assessed during the Dynamic Isotope Power Systems (DIPS) program (1975-1980) to develop $1 \mathrm{~kW}$-class RPSs and are currently being reconsidered in the FPS program for very high (hundreds of kWs) nuclear power generation in space. Rankine engines have the advantage of requiring smaller radiators, due to the higher heat transfer capacity of the two-phase flow working fluid; thus, Rankine are especially suited for very high power applications (of several hundreds of kWs or even MWs). Due to this feature, Rankine systems are not expected to compete directly with TPV.

On the contrary, both Stirling and Brayton engines are being also considered, along with TPV, for replacement of thermoelectrics in future RPS and FPS systems. Historical review about U.S. development on Brayton and Stirling engines for space applications can be found in $[26,27]$. In what follows, we briefly summarize these developments.

\subsubsection{Brayton engines}

The earliest Brayton engines for space applications were fabricated by AiReserach during the U.S. Brayton Rotating Units (BRU) project (1968-1978). Initial prototypes consisted of $2-10 \mathrm{~kW}_{\mathrm{e}}$ units that demonstrated long life performance (greater than $50,000 \mathrm{~h}$ ) and a high conversion efficiency of $32 \%$ at turbine (compressor) inlet temperatures of $1114 \mathrm{~K}(300 \mathrm{~K})$. Next to this project, mini-BRU units were developed to demonstrate high efficiency at power levels of $0.5-2$ $\mathrm{kWe}$. These units were used later, during the solar dynamic (SD) ground test demonstration (SD-GTD) project (1994-1998), to fabricate a $2 \mathrm{~kW}_{\mathrm{e}}$ solar powered prototype including a $\mathrm{LiF}-\mathrm{CaF}_{2}$ phase change material (PCM) (melting point of $1040 \mathrm{~K}$ and latent heat of
$789 \mathrm{~kJ} / \mathrm{kg}$ ) for thermal energy storage [28]. This prototype successfully demonstrated $29 \%$ heat-to-electricity conversion efficiency (17\% solarto-electric) and over $800 \mathrm{~h}$ of operation ( 372 cycles). The SD-GTD prototype was further characterized during the Jupiter Icy Moons Orbiter (JIMO) program (2000-2005). After JIMO cancellation, activities on Brayton engines continued at Barber Nichols Inc. with the aim of developing dual systems with redundant Brayton converters, and culminated with the fabrication of a $22 \mathrm{~kW}_{\mathrm{e}}$ first-of-a-kind test system.

To our knowledge, the latest developments on Brayton at NASA have been carried out within the Fission Surface Power (FSP) project (started in 2008) to develop $\sim 12 \mathrm{~kW}_{\mathrm{e}}$ nuclear reactor for surface power generation in lunar and Mars environments. The FSP system operated at low temperature $(\sim 900 \mathrm{~K})$ and used $\mathrm{CO}_{2}$ and $\mathrm{NaK}$ as working and heat-transfer fluids [29].

Little references are found for Brayton engines for their application to $\sim 100 \mathrm{~W}$ class RPS systems. The only reference we found is that of micro-machined Brayton engines that have been developed by Creare Inc. This system has expected efficiencies of $\sim 21 \%$ at turbine inlet temperature or $1055 \mathrm{~K}$, and it has already demonstrated dynamic behavior without noticeable degradation [3].

\subsubsection{Stirling engines}

The first developments of Stirling engines for space applications started in 1984 within the SP-100 program at NASA. The first Stirling prototype, the Space Power Demonstrator Engine (SPDE) (19841987), demonstrated power generation capacity of $17 \mathrm{~kW}_{\mathrm{e}}$ during more than $400 \mathrm{~h}$ of operation at hot-end temperature of $630 \mathrm{~K}$. Following the SPDE development, the so-called Component Test Power Convertor (CTPC) (1988-1993) was developed able to operate at increased temperature of $1050 \mathrm{~K}$. This unit demonstrated enhanced conversion efficiency (22\%) and more than $1500 \mathrm{~h}$ of operation. The high power Stirling development was temporally terminated at NASA after these projects until very recently, within the FPS program where a $12 \mathrm{~kW}_{\mathrm{e}}$ system, intended to be used in a nuclear reactor, has been fabricated [30]. This unit comprises two $6 \mathrm{~kW}_{\mathrm{e}}$ Stirling converters developed by SunPower Inc. and operates between a NaK primary coolant loop at $850 \mathrm{~K}$ and a water secondary coolant loop at $375 \mathrm{~K}$.

The development of small (100W-class) Stirling converters for RPS applications started in the late 90's, when NASA and Stirling Technology Company (STC) developed the 55-W Technology Demonstration Convertor (TDC). This unit was used as a baseline for the 110-W Stirling Radioisotope Generator (SRG110) (1997-2006) eventually developed by Lockheed Martin. Infinia (formerly STC) developed more than 20 converters of this kind that demonstrated over $26,000 \mathrm{~h}$ of operation. The SRG110 comprised two GPHS and two Stirling Converstor Assemblies (SCA) each producing about $60 \mathrm{~W}_{\mathrm{e}}$, resulting in an overall specific power of $\sim 3.6 \mathrm{~W}_{\mathrm{e}} / \mathrm{kg}$ (Table 1 ). Subsequent designs used the lower mass and higher efficient Advanced Stirling Convertor (ASC) developed by SunPower Inc., which demonstrated efficiencies of up to $38 \%$ for hot-end (cold-end) temperature of $1123 \mathrm{~K}(362 \mathrm{~K})$. These units were used during the development of the Advanced Stirling Radioisotope Generator (ASRG), which has been designed to produce $\sim 160 \mathrm{~W}_{\mathrm{e}}$ with a targeted overall specific power greater than $8 \mathrm{~W}_{\mathrm{e}} / \mathrm{kg}$. The ASRG Engineering Unit \#2 (EU2) was completely assembled in August 2014 at NASA GRC utilizing two ASC-E3 units [31]. Actual specific powers of $\sim 4.1 \mathrm{~W} / \mathrm{kg}$ were eventually reported for the full ASRG system [32].

Besides of radioisotope systems, the ASC unit has recently become the baseline technology for power conversion in a new 1-kWe class of nuclear reactors developed at NASA for future science and human exploration [16,17]. Since 2015, the Stirling Cycle Technology Development Project (SCTDP) continues development of Stirling systems and subsystems to increase performance, reducing mass and improving system reliability [33]. 


\section{TPV energy in space applications}

TPV converters have been explored for two main space power applications: RPS and solar thermal. In RPS applications, TPV competes mostly with Stirling engines to substitute the more mature and less efficient thermoelectric converters. In solar thermal applications, TPV is been proposed to develop a new kind of solar thermal power generator that could be eventually used in harsh environments, such as the Van Allen orbits, and that could integrate extremely energetically dense thermal energy storage. The thermal energy storage option fits particularly well in applications where a constant supply of heat and electricity is needed, such as in solar thermal propulsion systems. In what follows we describe the historical development of these different applications of the TPV energy.

\subsection{Radioisotope TPV}

Radioisotope TPV (RTPV) was proposed in mid 90's [34] as an alternative to RTG and RSG with potential to achieve specific powers beyond $15 \mathrm{~W} / \mathrm{kg}$ [12,35-37]. This is $3-5$ times greater than current SRG110 $(3.6 \mathrm{~W} / \mathrm{kg})$, MMRTG $(2.8 \mathrm{~W} / \mathrm{kg})$ and GPHS-RTG $(5.1 \mathrm{~W} / \mathrm{kg})$ units. Thus, research efforts to develop RTPV generators started in 2003, when NASA issued contracts to Edtek and Creare to develop a RTPV system using electrically heated thermal source to emulate a $250 \mathrm{~W}_{\text {th }}$ GPHS unit. The TPV converter used $0.6 \mathrm{eV}$ InGaAs monolithic interconnected modules (MIMs) [38] fabricated by Emcore and interference/plasma filters made by Rugate. A $10 \times 10 \mathrm{~cm}$ TPV array containing 16 MIMs, each of them comprising 25 series-interconnected InGaAs subcells, was fabricated to provide $\sim 50 \mathrm{~W}_{\mathrm{e}}$ at heat source temperature of $1077^{\circ} \mathrm{C}$, demonstrating conversion efficiencies in the range of $18-20 \%$. A maximum specific power of $\sim 17 \mathrm{~W} / \mathrm{kg}$ has been predicted for this system at MIM temperatures in the range of 50$70{ }^{\circ} \mathrm{C}$ (radiator temperature of $\sim 60-80^{\circ} \mathrm{C}$ ). However, more recent studies have concluded that these estimations were extremely optimistic, and have predicted considerably lower attainable values, typically in the range of $6-8 \mathrm{~W} / \mathrm{kg}[37,39]$.

The main bottleneck for the achievement of higher specific powers in RTPV systems is heat rejection radiator mass. Large radiators are needed to keep the cell at low temperatures; thus, the TPV cell temperature must fulfill an optimum tradeoff between the radiator size and the TPV cell conversion efficiency. Smaller radiator enables lower weight at the expense of higher cell temperature and lower output power and conversion efficiency [12].

Therefore, TPV cell degradation at high temperatures is one of the main concerns in RTPV systems. Several kinds of degradation tests have been conducted in state of the art $0.6 \mathrm{eV}$ InGaAs MIM devices. For instance, MIMs have been tested at $90{ }^{\circ} \mathrm{C}$ during more than $4000 \mathrm{~h}$ demonstrating no relevant degradation. Another very important aspect of RTPV is the eventual TPV cell degradation under neutron radiation from the $\mathrm{Pu}-238$ source. Neutron radiation tests were carried out by the Naval Research laboratory in the full TPV arrays to predict a $20 \%$ degradation of the TPV converter by the end of a 14-year mission [12], which compares to $14 \%$ for the MMRTG system. More recent research has been carried out within the micro-isotope power system (MIPS) program funded by DARPA to develop the first $\mathrm{mW}$-scale radioisotope fueled RTPV system [40]. Within this program, degradation tests were performed on $0.6 \mathrm{eV}$ InGaAs MIMs using both $\mathrm{Pu}-238$ and $\mathrm{Cm}-244$ radioisotope sources. The MIMs were exposed to $\mathrm{Cm}-244$ over 120 days, which is equivalent to more than 100 years of operation under $\mathrm{Pu}-238$, and showed less than $1 \%$ of degradation per year, which includes the temperature decay of the heat source and cell degradation due to neutron damage.

The latest development of RTPV systems have been carried out by General Atomics to develop complete hermetically sealed 1-10 W-scale RTPV systems [40]. These units have been tested using electric heaters demonstrating conversion efficiency near $8 \%$. The lower efficiency with respect to earlier NASA developments is attributed to the scaling issues of TPV for very small powers. These units were ready for testing using Pu-238 heat source at Los Alamos National Laboratory in 2016.

\subsection{Solar $T P V$}

Solar TPV (STPV) [41-45] has possible applications in near-sun space missions (Earth orbit or closer). The key advantage of STPV is the possibility of integrating extremely energetically dense thermal energy storage [46-49], theoretically enabling the development of a compact solar powered device that produces a constant power supply. Despite of its high theoretical potential, it is still premature making any confident estimation of the expected specific power of the storageintegrated STPV system, or whether it may outperform the current solution based on a combination of solar panels and electrochemical batteries. The only flight experiment carried out so far on thermal energy storage at temperatures near that of required in TPV applications concerned the use of molten lithium fluoride PCMs, at $\sim 1050^{\circ} \mathrm{C}$, during the Space Shuttle Thermal Energy Storage flight experiments [50].

Thermal energy storage is particularly advantageous for solar thermal propulsion (STP) systems, which are being investigated to replace the conventional chemical and electrical rockets. STP uses a solar heated propellant (e.g. Ammonia) that is ejected at very high temperatures (well above $1200^{\circ} \mathrm{C}$ ) to provide very high specific impulses beyond $300 \mathrm{~s}$ and velocity increments of several hundreds of $\mathrm{m} / \mathrm{s}$. In these systems, thermal energy storage is important to enable the STP during eclipses. Very recently, both experimental and theoretical research has been started by Air Force Research Laboratory (AFRL), ERC Inc, USC and UCCS to evaluate the feasibility of using silicon and boron PCMs for latent heat energy storage to augment STP in microsatellites operating in LEOs [51-55]. Silicon and Boron have remarkably high latent heats of $1800 \mathrm{~J} / \mathrm{g}$ and $4650 \mathrm{~J} / \mathrm{g}$ and melting temperatures of $1410^{\circ} \mathrm{C}$ and $2540^{\circ} \mathrm{C}$, respectively, which perfectly matches the STP requirements. In [51-55], TPV is considered as an ideal technological option for generating electricity in these systems, whose operation temperature is excessive for thermoelectric converters.

STPV may also offer some advantages for missions in high radiation environments [12], such as in Mid Earth orbits (MEO) coinciding with the Van Allen radiation belts, where PV systems degrade significantly in short periods of time. In contrast, TPV cells in STPV system arrangements are shielded by the emitter, leaving only resistant materials exposed to radiation.

Finally, STPV could be also used in missions very near to the sun, where the solar flux is too intense for the direct incidence in solar cells. Some examples are the ESA missions Solar Orbiter [56] and the Bepicolombo [57], or the NASA's solar probe plus mission [58], that will reach the closest distance to the sun's surface of 9.5 sun-radii. The NASA's spacecraft will be protected from solar flux by a $2.7 \mathrm{~m}$ diameter and $17 \mathrm{~cm}$-thick $\mathrm{C}-\mathrm{C}$ composite shield, which will reach high temperatures of nearly $1400^{\circ} \mathrm{C}$ at the closest distances to the Sun. TPV, was considered during the initial design phase of this mission for converting the radiant heat emitted by the thermal shield. Final design will use two directly-exposed actively-cooled PV arrays comprising state of the art triple-junction CPV cells. Each PV array is partially shadowed by the thermal shield to limit power generation to $\sim 300 \mathrm{~W}_{\mathrm{e}}$ and cell temperatures to $\sim 120^{\circ} \mathrm{C}$.

Early experimental research on STPV was carried out by McDonnell Douglas in the mid 90's [59] and by EDTEK in the early 2000's [60] for both space and terrestrial applications. Both systems were thoroughly characterized under concentrated sunlight demonstrating high emitter temperatures (up to $1360{ }^{\circ} \mathrm{C}$ ) and power densities $\left(\sim 0.9 \mathrm{~W} / \mathrm{cm}^{2}\right.$ ). However, no experimental system efficiencies were reported. In late 2000 s, UPM and Ioffe Institute developed STPV systems for terrestrial applications within the frame of the FULLSPECTRUM project, even- 
tually leading to the first reported experimental efficiency for a full STPV system of $\sim 1 \%$ [61]. Two years later, a MIT team reported a STPV device with conversion efficiency of $3.2 \%$ [44] by using optimized nanostructured selective emitter and InGaAsSb TPV cells. This result renewed the interest in STPV devices and very recently, Virginia University and MIT have independently reported the highest STPV efficiencies to date of $6.2 \%$ [62] and $6.8 \%$ [63], respectively, which illustrates the fast development of STPV during the past few years. Probably, scaling to larger system sizes will be the next step towards the achievement of high efficient STPV devices.

\section{Next generation TPV concepts for space applications}

Next generation concepts for TPV conversion in space application are aimed at increasing the specific power of the spacecraft $(\mathrm{W} / \mathrm{kg})$. This figure of merit (FOM) has two contributions: power and mass. On the one hand, high TPV conversion efficiency is important to reduce the amount of rejected heat and subsequently reduce the required size of the radiator heat sink, which is the main contributor to the TPV generator mass. On the other hand, high power density $\left(\mathrm{W} / \mathrm{cm}^{2}\right)$ is also important to minimize the heat source area for producing the required nominal power.

\subsection{Power density or efficiency?}

Efficiency and power density are different FOMs of TPV converters, in some cases inversely proportional [10]. This is because in a TPV arrangement, part of the radiant heat may be turned back to the heat source, not representing a loss of energy. Turning back most of the thermal radiation, leaving only a very narrow spectral band reaching the TPV cell theoretically increases the TPV conversion efficiency, at the expenses of reducing the output electrical power density. Ideally, novel TPV concepts should improve both FOMs simultaneously. However, the majority of them are aimed at boosting mostly one of them (Table 2). Therefore, in order to choose the appropriate TPV concept, it is essential to determine whatever it is relevant to increase the power density or the conversion efficiency of the TPV device, and this depends on the final application of the TPV converter.

In open TPV systems, such as STPV (heat is supplied externally), high TPV power density is particularly important in order to reach an optimum energy balance in the emitter that maximizes the power

Table 2

The aspiration potential of novel TPV concepts. $\sim$ means that no significant improvement is expected.

\begin{tabular}{llll}
\hline TPV concept & $\begin{array}{l}\text { Power } \\
\text { density }\end{array}$ & Efficiency & Best application \\
\hline $\begin{array}{l}\text { Sub-bandgap spectral } \\
\text { control }\end{array}$ & $\sim$ & $\uparrow \uparrow$ & STPV/RTPV \\
$\begin{array}{l}\text { Narrow-band spectral } \\
\text { control }\end{array}$ & $\downarrow \downarrow \downarrow$ & $\uparrow \uparrow \uparrow^{\mathrm{a}}$ & RTPV (high T) \\
$\begin{array}{l}\text { Multiband TPV cells } \\
\text { Near-field TPV (NFTPV) }\end{array}$ & $\uparrow$ & & \\
Thermophotonics (TPX) & $\uparrow \uparrow \uparrow$ & $\uparrow$ & STPV/RTPV \\
Light-pipe TPV (LTPV) & $\uparrow \uparrow$ & $\sim^{\mathrm{b}, \mathrm{d}}$ & STPV \\
Thermionic-PV (TIPV) & $\uparrow$ & $\sim^{\mathrm{c}}$ & STPV \\
\hline
\end{tabular}

a The efficiency increment requires of extremely low out-band emission losses, not readily attainable with current state of the art materials.

b NFTPV assisted by surface-modes may enable higher efficiencies at the expenses of reduced power density. In other cases, spectral control issues in NFTPV are expected to negatively impact on the conversion efficiency.

${ }^{c}$ TPX efficiency strongly depends on the emitter bandgap, emitter bias voltage and the ideality factors, such as the external luminescent quantum efficiency. Generally, TPX provides lower conversion efficiencies than TPV.

${ }^{d}$ An efficiency increment is expected due to the higher generation rate in the TPV cell (due to the higher power density) that overshadows the recombination, but it is premature determining whether this increment will overshadow the conductive thermal losses through the light pipe. transferred to the TPV cells and minimizes the re-emission losses, i.e. maximizes the overall solar-to-electricity conversion efficiency. On the contrary, in closed TPV systems, such as RTPV (heat is generated internally) the TPV conversion efficiency is the key parameter. This is because in this case, the power transferred to the TPV cells is a constant; thus, increasing the efficiency of TPV directly produces an increment in the power density and a reduction of the rejected heat. In closed TPV systems it is also important to distinguish between those concepts that enable high efficiency at the expenses of increasing the equilibrium emitter temperature (e.g. restricting the radiative exchange between the emitter and the cells to a very narrow spectral band) and those that enable higher efficiency at lower emitter temperatures (e.g. those broadening the spectral response of the TPV cell). The later ones (e.g. multiband cells) are characterized by enabling an increment of both the efficiency and the power density at a constant emitter temperature; thus, they are particularly appealing for both closed and open TPV system applications.

A number of TPV concepts have been proposed to enhance both the efficiency and the power density of TPV devices (Table 2). They may be classified in those aimed at improving the performance of an independent TPV components (mainly the TPV cell and the spectral control elements), and those targeted to develop a novel conceptual TPV system arrangement. In what follows, we briefly describe each of them.

\subsection{Novel concepts for TPV components}

\subsubsection{Spectral control}

The TPV research has been particularly prolific during the past few decades in the development of solutions for tuning the net spectral radiative flux between the emitter and the TPV cell. These solutions can be classified among those directly engineering the hot side of the converter, i.e. the TPV emitter (e.g. photonic crystals, rare-earth compounds, hyperbolic metamaterials, etc.) and those engineering the cold side, i.e. TPV cell (e.g. reflectors and filters). It is out of the scope of this work providing a review of all these options (comprehensive reviews can be found in $[6,7,45])$. The common goal of all of them is to maximize (minimize) the net flux of photons with energies above (below) the absorption threshold of the TPV cell. In some cases, highly energetic photons are also rejected, resulting in narrow-band radiative exchange that increases the TPV conversion efficiency at the expenses of reducing the output electrical power density (Table 2). Current state of the art spectral control elements enable very high spectral control efficiencies, beyond $80 \%$ [64] and novel conceptual designs promise near-term spectral efficiencies of $~ 90 \%$ [65]. Current technological challenge of selective thermal emitters is the thermal stability at high temperatures $[66,67]$. This challenge does not exist in those spectral control elements implemented in the cold side.

\subsubsection{TPV cells}

The key parameter determining the TPV cell performance is the semiconductor band gap energy, whose optimum value for space applications is that of resulting in the highest specific power of the spacecraft. Figs. 5a and 6 a show the calculated specific power and the radiator area to power ratio of a RTPV generator as a function of the (single junction) TPV cell bandgap and temperature, as predicted by the RTPV model described in the Appendix A. Table 3 provides greater information of some specific design results. In the calculations, the TPV cells are assumed to have a BSR reflectivity of $90 \%$ and internal photoluminescence efficiency of $65 \%$, independently of the bandgap energy. These values have been taken in order to fit the predicted specific power for RTPV given in $[37,39]$.

According to this model, specific powers of 7.5 and $8 \mathrm{~W} / \mathrm{kg}$ are theoretically attainable with TPV cell bandgap of $0.6 \mathrm{eV}$ and $0.5 \mathrm{eV}$, respectively, both operating at a cell temperature of $50^{\circ} \mathrm{C}$, which represents the optimum trade-off between power output and radiator mass. The former $(0.6 \mathrm{eV})$ represents the case of the state of the art 
Single junction TPV cell

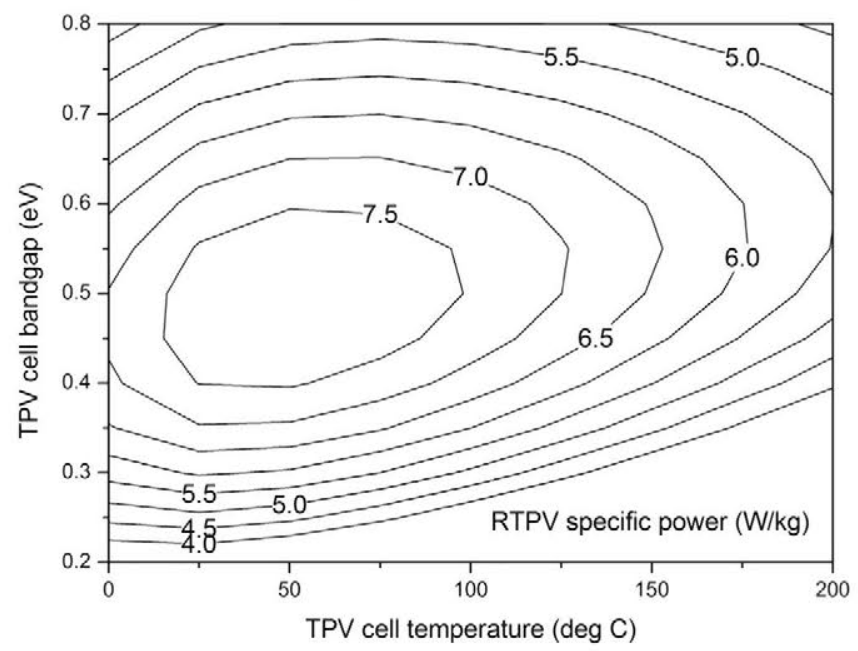

(a)

Dual junction TPV cell

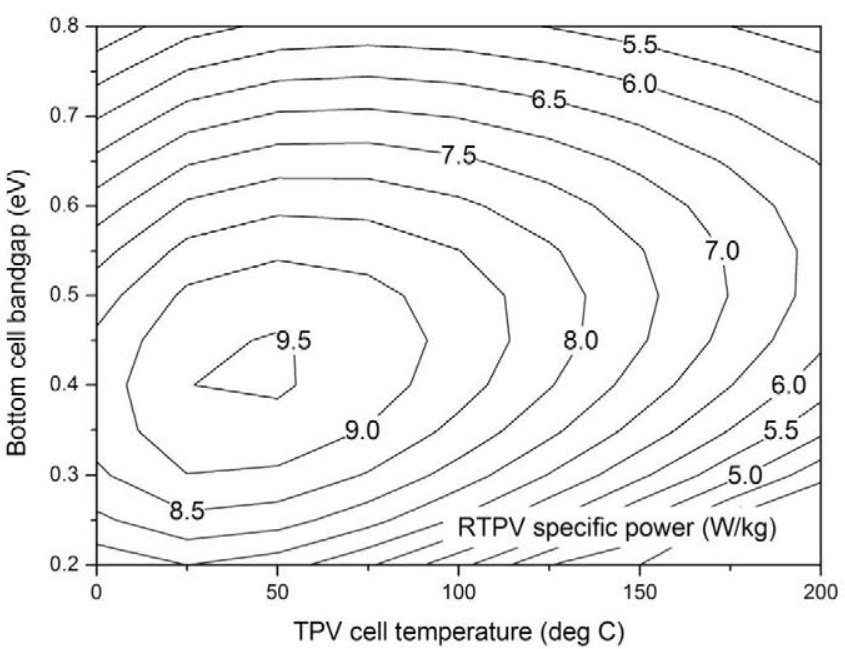

(b)

Fig. 5. Specific power of a RTPV generator using (a) single junction and (b) dual junction TPV cells as a function of TPV cell temperature and bandgap (bottom cell bandgap in the case of dual junction cell). The top-cell for dual junction TPV cell is optimized to provide the maximum power and to be current matched to the bottom-cell.

InGaAs MIM devices used in Creare's $250 \mathrm{~W}_{\text {th }}$ RTPV units [12]. The later $(0.5 \mathrm{eV})$ could be implemented using InGaAsSb compounds on $\mathrm{GaSb}$ substrates [68]. However, the actual benefit of using $0.5 \mathrm{eV}$ InGaAsSb (on $\mathrm{GaSb}$ ) instead of $0.6 \mathrm{eV}$ InGaAs (on InP) is doubtful. This is because of the lack of a semi-insulating substrate, lattice matched to Sb-compounds, that has very low free carrier absorption to enable the efficient implementation of MIM technology with back surface reflectors, something that is possible with InP substrates.

It must be noticed that the values shown above are determined for a relatively low emitter temperature of $\sim 1000^{\circ} \mathrm{C}$ (see Table 3). Eventual future TPV applications (e.g. solar powered) may operate at higher temperatures, enabling higher conversion efficiencies and power densities. In this case, other optimal semiconductors compounds exist with bandgap ranging from 0.60 to $0.74 \mathrm{eV}$, such as $\mathrm{Ge}, \mathrm{GaSb}$, and InGaAs [6].

Multiband TPV (MBTPV) cells are perhaps, the most promising solution for producing a significant increase in the specific power of TPV systems in the short term (Table 2). MBTPV cells are characterized

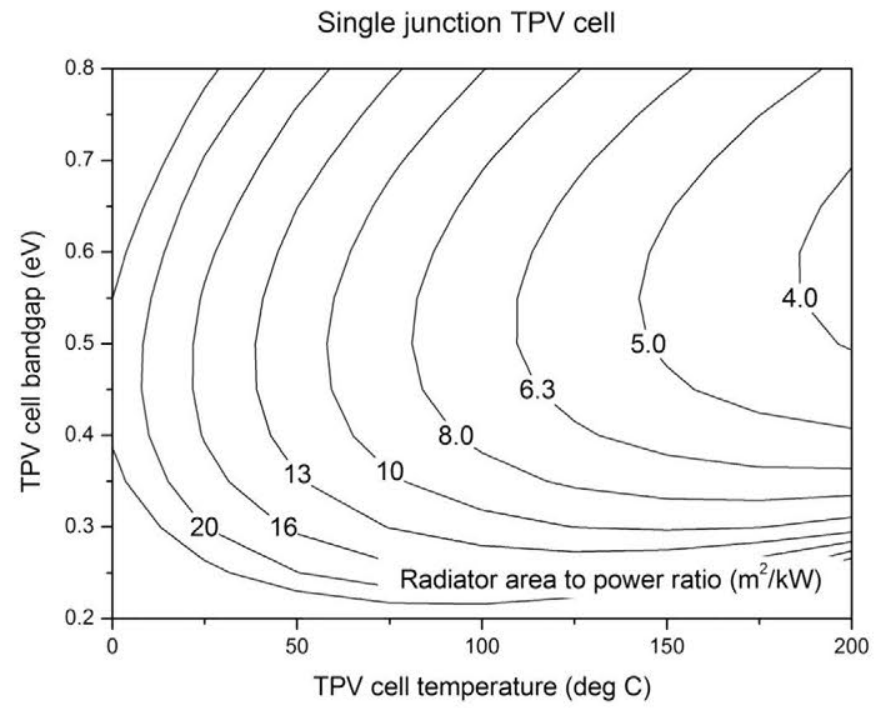

(a)

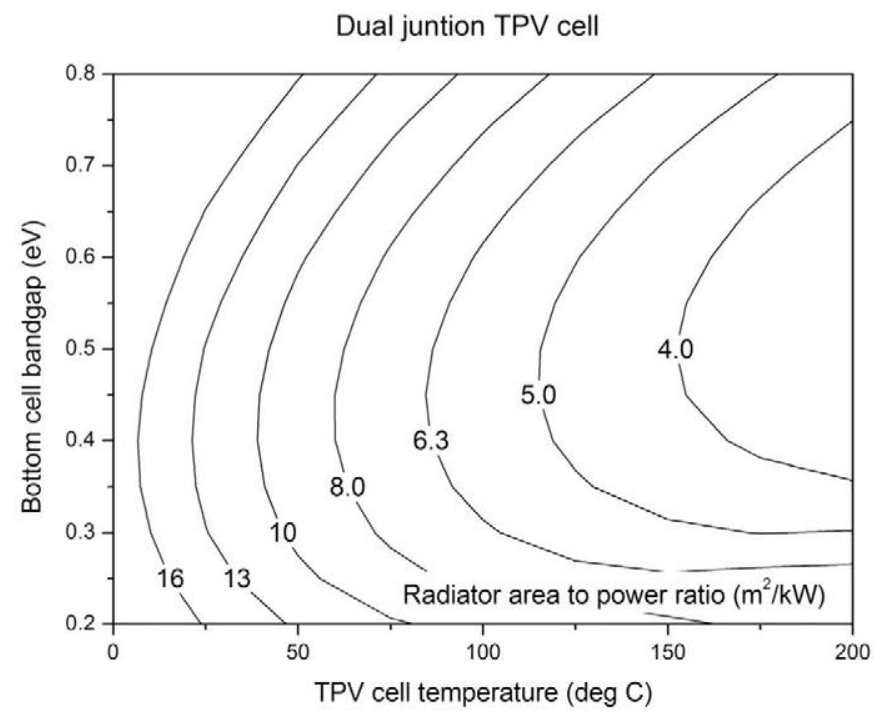

(b)

Fig. 6. Radiator area to power ratio $\left(\mathrm{m}^{2} / \mathrm{kW}\right)$ of a RTPV generator using (a) single junction and (b) dual junction TPV cells as a function of TPV cell temperature and bandgap (bottom cell bandgap in the case of dual junction cell). The top-cell for the dual junction TPV cell (b) is optimized to provide the maximum power and to be current matched to the bottom-cell.

by a broadened spectral response that results in a higher amount of power generated from the radiant heat, which produces an increment in both the power density and the conversion efficiency [10]. Multijunction TPV (MJTPV) is the most typical kind of MBTPV converter. Similarly to multijunction solar cells, in MJTPV devices, at least two subcells, made of a different semiconductor material, are stacked so that each of them transforms into electricity a different part of the incident spectrum with higher efficiency.

Figs. 5-b and 6-b, and Table 3 show the specific power of RTPV generator using current-matched dual-junction converters, as a function of the bottom cell bandgap (top-cell bandgap is optimized). According to these simulations, specific powers as high as $\sim 9.5 \mathrm{~W} / \mathrm{kg}$ are theoretically attainable by using $0.40 \mathrm{eV}$ and $0.56 \mathrm{eV}$ bandgap semiconductors for the bottom and top cell, respectively. This represents a $\sim 27 \%$ increment in the specific power that is attainable with current state of the art $0.6 \mathrm{eV}$ InGaAs TPV cells. This improvement is 
Table 3

Theoretical performance of the 250 Wth RTPV system described in the appendix and utilizing different kinds of TPV cells at different operating temperatures.

\begin{tabular}{|c|c|c|c|c|c|c|c|c|}
\hline$E_{\text {bott }}(\mathrm{eV})$ & $E_{\text {top }}(\mathrm{eV})$ & $T_{\mathrm{c}}\left({ }^{\circ} \mathrm{C}\right)$ & $T_{\mathrm{e}}\left({ }^{\circ} \mathrm{C}\right)$ & $P_{\text {out }}\left(\mathrm{W}_{\mathrm{e}}\right)$ & $P_{\text {out }} / A_{\mathrm{c}}\left(\mathrm{W}_{\mathrm{e}} / \mathrm{cm}^{2}\right)$ & Efficiency (\%) & $A_{\mathrm{rad}}{ }^{\mathrm{a}}\left(\mathrm{m}^{2} / \mathrm{kW}_{\mathrm{e}}\right)$ & RTPV Specific power $(\mathrm{W} / \mathrm{kg})$ \\
\hline 0.60 & - & 25 & 1038 & 47.2 & 0.295 & 22.1 & 16.5 & 7.18 \\
\hline $0.60^{\mathrm{b}}$ & - & $25^{\mathrm{b}}$ & 946 & 26.1 & 0.163 & 12.2 & 33.0 & 3.85 \\
\hline 0.50 & - & 25 & 1010 & 50.8 & 0.317 & 23.8 & 15.1 & 7.65 \\
\hline 0.40 & 0.554 & 25 & 984 & 61.1 & 0.382 & 28.6 & 11.3 & 9.49 \\
\hline 0.60 & - & 50 & 1038 & 44.2 & 0.276 & 20.7 & 11.7 & 7.46 \\
\hline 0.60 & - & 75 & 1038 & 41.2 & 0.257 & 19.3 & 8.9 & 7.43 \\
\hline 0.50 & - & 50 & 1010 & 47.0 & 0.293 & 22.0 & 10.9 & 7.96 \\
\hline 0.40 & - & 50 & 983 & 44.7 & 0.280 & 20.9 & 11.6 & 7.56 \\
\hline 0.60 & 0.730 & 50 & 1038 & 49.4 & 0.309 & 23.1 & 7.9 & 8.39 \\
\hline 0.55 & 0.683 & 50 & 1024 & 52.3 & 0.327 & 24.5 & 7.8 & 8.92 \\
\hline 0.50 & 0.639 & 50 & 1010 & 54.5 & 0.341 & 25.5 & 7.71 & 9.31 \\
\hline 0.40 & 0.555 & 50 & 984 & 55.9 & 0.350 & 26.2 & 7.65 & 9.56 \\
\hline 0.35 & 0.519 & 50 & 972 & 54.8 & 0.342 & 25.6 & 7.70 & 9.35 \\
\hline
\end{tabular}

a There are two radiators, one for each TPV array, accounting for the total radiator area.

b TPV cells without BSR.

attributed to the fact that multijunction cells produce higher power density and efficiency at lower emitter temperatures (see Table 3); thus, the heat that must be rejected from the TPV cells is considerably lower, enabling a significant reduction (34\%) in the radiator size, from 11.7 to $7.7 \mathrm{~m}^{2} / \mathrm{kW}_{\mathrm{e}}$ (see Fig. 6 and Table 3 ).

Experimental MJTPV cells have been fabricated using InGaAs(P)/ InGaAs structures [69-71] with bandgaps of $0.55-0.63$ (bottom) and 0.72-0.74 eV (top) demonstrating good electric performance. According to the model used in this work, these bandgap combinations would enable specific power densities of up to $\sim 8.4 \mathrm{~W} / \mathrm{kg}$ (e.g. $0.6 \mathrm{eV} /$ $0.73 \mathrm{eV}$ ), which is already $12 \%$ higher than what is predicted for the current state of the art $0.6 \mathrm{eV}$ devices.

The bottleneck to develop optimal MJTPV devices concerns the development of the bottom cell. InGaAsSb (on GaSb) could be used in principle, but bandgap energies below $\sim 0.5 \mathrm{eV}$ are very challenging in this material due to miscibility gap issues [72,73]. Thus, InAs and InAsSbP (on InAs) emerge as the most promising options for realizing optimal multijunction TPV cells for RTPV applications, with attainable bandgaps in the range of $0.3-0.5 \mathrm{eV}$ [74]. For these materials, it is possible to grow lattice-matched compounds with high bandgap, such as AlAsSb, to fabricate the buffer and window layers. Experimental TPV cells have been developed using InAs (bandgap of $0.35 \mathrm{eV}$ ) [75-77] and InAsSbP on InAs (bandgap of $0.39 \mathrm{eV}$ ) [73] materials, demonstrating high photocurrent generation, but still low performance in terms of fill factor and open circuit voltages. According to [74], output voltage and fill factor of these devices are currently limited by technological rather than fundamental issues; thus, higher performance is eventually attainable improving the semiconductor fabrication process.

Other alternatives to fabricate materials with very low effective bandgap are quantum nanostructures, mostly quantum wells (QWs) [78]. The main benefit of these concepts is the greater versatility on the material selection, since quantum nanostructures are not necessary lattice-matched to the semiconductor substrate and the optical absorption spectrum may be tuned by the quantum nanostructure dimensions. It is noticeable that quantum nanostructures enable a significant suppression of non-radiative recombination [79], which is particularly relevant for low bandgap semiconductors.

Other kinds of MBTPV cells include those manufactured with any kind of intermediate band material [80] or those using quantum nanostructures [81]. It worth to mention the MBTPV devices based on the quantum-cascade photodetector (QCP) concept [82]. This device takes advantage of the very low energetic bound-to-continuum intersubband transition in the, e.g. InGaAs/AlAsSb, QWs that enable the absorption of very low energetic photons (below $0.3 \mathrm{eV}$ ). A particularity of this device is that only polarized light can be absorbed; thus, some kind of waveguide or filter has to be integrated in the TPV cell structure.

\subsection{Novel conceptual TPV systems}

\subsubsection{Near-field TPV}

In near-field TPV (NFTPV) [83] the emitter and the TPV cell are separated a very short distance, typically below $1 \mu \mathrm{m}$. In this arrangement, the evanescent modes that are thermally excited within the emitter, can tunnel through the small gap and be absorbed in the TPV cell. This enables a significant increase in the radiative energy flux and the output power density.

The theory of NFTPV predicts output power density enhancements of several orders of magnitude. Park et al. calculated $\sim 10$-fold power enhancement for $100 \mathrm{~nm}$ gap distance and up to 100 -fold for separation gaps slightly below $10 \mathrm{~nm}$ [84]. However, conversion efficiency is not necessarily higher in NFTPV arrangements. This is partially due to the strong surface recombination in the TPV cell (particularly relevant for near-field arrangements) and to the difficulty of implementing spectral control in the near-field, which additionally leads to important thermal management issues $[85,86]$.

In the near-field, the long-wavelength evanescent modes can tunnel through the small vacuum gap; thus, some kinds of spectral control elements, such as front side filters and multilayered emitters, are inefficient. A possible solution consists of using a back surface reflector (BSR), as proposed in [84], to reflect back to the emitter those photons that propagate all through the TPV cell and reach the back side. Other solutions consist of using emitter materials supporting surface phonon/plasmon polaritons. These optical modes can be thermally excited and enormously contribute to the radiative energy transfer at very small gaps (below $\sim 30 \mathrm{~nm}$ ) [85] and selective wavelengths, corresponding to the material phonon/plasmon resonance frequencies. Unfortunately, typical resonance frequencies of materials found in nature are either too high (plasmon polaritons of metals) or too low (phonon polaritons in polar materials). Extremely low bandgap NFTV using InSb $(0.17 \mathrm{eV}) \mathrm{TPV}$ cell covered with graphene and using h-BN emitter has been proposed for very low temperature applications [87]. A recent study [88] describes the theoretical advantage of using TPV cells and emitters with quantum confined dimensions (e.g. QDs, nanowires or QWs) for NFTPV arrangements. This is attributed to the quasi-ideal Dirac distribution of the joint density of electronic states that enables quasi-monochromatic energy transfer between the emitter and the cell.

The experimental proof of concept of NFTPV has been independently carried out by Di Matteo [89] and Hanamura [90], demonstrating a remarkable enhancement in the photocurrent density for gaps below $1 \mu \mathrm{m}$. Concerning the development of final NFTPV devices, recent developments have demonstrated the feasibility of manufacturing uniform parallel gaps with ceramic micro-spacers that enable the suppression of conductive heat transfer respect to the radiative heat 
transfer [91].

\subsubsection{Thermophotonics}

Thermophotonics (TPX) [92] is a generalization of TPV in which the emitter is able to emit photons not only due to thermal excitation, but also due to electrochemical reactions driven by an external voltage bias applied to the (thermo-luminescent) emitter, which operates as a hot light emitting diode (LEDs). If the external electroluminescence quantum efficiency of the emitter is sufficiently high, there will be a net power gain in the device, i.e. the electricity consumption in the emitter will be smaller than the power gained in the TPV cell due to the extra electroluminescent emission. This is explained by the higher energy of the emitted photons (roughly equaling the bandgap energy) than that of the recombined electron-hole pairs (equaling the quasi-Fermi energy difference in the emitter contacts). This energy difference accounts for the heat (entropic term) carried by the electroluminescent photons radiated by the emitter.

External photoluminescent quantum efficiencies of $\sim 96 \%$ have been experimentally measured in $\mathrm{GaInP} / \mathrm{GaAs}$ double heterostructures coupled to a $\mathrm{ZnSe}$ dome and operating at room temperature [93]. This value is already close to the one needed to take advantage of the TPX effect ( $>98 \%$ ). Very high external electroluminescent quantum efficiencies may be attainable in the future by using near-field arrangements, as described in [94], were evanescent modes may tunnel from the emitter to the cell.

The TPX effect has been recently observed experimentally at low temperatures (temperature gradient of $20^{\circ} \mathrm{C}$ ) in a monolithic arrangement, where both the luminescent emitter and the TPV cell are integrated into the same semiconductor device structure [95]. Due to the almost constant refraction index all through the device, this arrangement enables the highest luminescent coupling between the emitter and the cell, at the expenses of strongly limiting the attainable temperature difference between the emitter and the cell due to conduction heat losses.

\subsubsection{Light-pipe TPV (LTPV)}

LTPV was proposed in 1997 [96] and reassessed theoretically in 2007 [97]. The idea consist of using a medium with refraction index $\mathbf{n}$ $>1$ in between the emitter and the TPV cell; thus, the radiative energy transfer is increased by a factor $\mathrm{n}^{2}$. The obvious challenge is impeding too large thermal conductivity losses through the optical pipe. No further experimental developments have been published so far on this concept.

\subsubsection{Hybrid thermionic-photovoltaic converters (TIPV)}

TIPV converters [98] have been recently proposed to increase the power density of TPV by means of enabling the simultaneous emission of photons and electrons from the emitter. The electron and photon fluxes are independently converted into electricity in the thermionic and TPV cell, respectively. A power density twice as great as that of independent TPV and thermionic devices is found theoretically feasible. The main technological challenge concerns the fabrication of a transparent and electrically conductive anode with a low work function. Possible candidates for the anode include thin metallic layers, and negative electron semiconductors, among others.

\section{Conclusions}

An overview of the development of TPV and that of the main competing technologies in the field of space power generation has been provided. TPV technology is particularly well suited for small-medium systems, with output powers in the range of few tens to hundreds of $\mathrm{W}_{\mathrm{e}}$. In this power range, TPV promises one of the highest specific powers among the other competing technologies. Main applications of TPV are radioisotope and solar power generators. Radioisotope TPV systems comprising $0.6 \mathrm{eV}$ InGaAs cells and operating at $\sim 1000{ }^{\circ} \mathrm{C}$ have already demonstrated high efficiencies of $\sim 20 \%$ and projected (realistic) specific powers of 6-8 W/kg. Current efforts are focusing on demonstrating long term reliability, including radiation damage of TPV cell semiconductor. In solar TPV, the main advantage concerns the possibility of integrating high temperature $\left(>1400^{\circ} \mathrm{C}\right)$ latent heat storage, with potential to reach ultra high energy densities of up to $\sim 4 \mathrm{MJs} / \mathrm{kg}$. This is particularly relevant for solar thermal propulsion applications, in which very high impulse and velocity increments are needed. Novel TPV concepts could eventually improve the TPV performance beyond that of current state of the art $0.6 \mathrm{eV}$ InGaAs devices. In particular, we have shown that next generation low bandgap multijunction TPV cells that were eventually used in radioisotope TPV systems could provide $27 \%$ gain in the specific power (up to $\sim 9.5 \mathrm{~W}$ / $\mathrm{kg}$ ) and require $34 \%$ smaller radiators $\left(7.7 \mathrm{~m}^{2} / \mathrm{kW}\right)$ than that of predicted for current state of the art $0.6 \mathrm{eV}$ TPV devices.

\section{Acknowledgement}

This work has been carried out under a programme of, and funded by, the European Space Agency (Contract No. 4000115109/15/NL/ $\mathrm{FE})$. In particular, the authors acknowledge the very fruitful discussions to Dr. Jose Ramón González and Dr. Carsten Baur, from the European Space Agency. The view expressed in this publication can in no way be taken to reflect the official opinion of the European Space Agency.

\section{Appendix A. RTPV model}

In order to evaluate the improvement potential of MJTPV cells for space applications we have developed a simplified RTPV system model that accounts not only for TPV generation, but also the GPHS unit and radiator mass. The model includes a TPV optical cavity model that accounts for both radiative and non-radiative recombination in the TPV cells and incorporates a BSR. The RTPV system has been modeled combining the approaches in [12,37,39], and taking the following assumptions:

1. GPHS units: $N_{m}=1$

2. GPHS unit mass: $M_{\text {GPHS }}=1.61 N_{m}+3.01 N_{m}^{0.455}$ (from [39])

3. GPHS power (BOM): $P_{\text {GPHS }}=250 \mathrm{~W}_{\mathrm{th}}$ (from [12])

4. Emitter emissivity (polished tantalum): $\varepsilon_{e}=217.349 \lambda^{-0.948}$ (from [37])

5. Parasitic thermal losses: $\eta_{\text {loss }}=0.17$ (from [12])

6. TPV array area (two-sides cavity): $A_{T P V}=160 \mathrm{~cm}^{2}$ (from [12])

7. Temperature drop from TPV cell to heat rejection radiator: $\Delta T_{\text {rad }}=T_{c}-T_{\text {rad }}=12{ }^{\circ} \mathrm{C}$ (from [12])

8. Heat rejection radiator emissivity: $\varepsilon_{\text {rad }}=0.9$ (from [12])

9. Background Temperature of Space: $T_{\text {space }}=200 \mathrm{~K}$ (from [12]) 
10. Heat rejection radiator mass per unit surface area: $M_{\text {rad }}=2.5 \mathrm{~kg} / \mathrm{m}^{2}$ (from [39])

11. Emitter-to-cell view factor: $F_{\mathrm{ec}}=1$

12. Cell-to-cell view factor: $F_{\mathrm{cc}}=0$

Using these data, the specific power of the RTPV generator is obtained from:

$P=\frac{A_{T P V} p_{T P V}}{M_{G P H S}+A_{r a d} M_{r a d}}$

The radiator area $A_{\text {rad }}$ required to keep the cells at temperature $T_{c}$ is obtained from the following energy balance equation:

$A_{\varepsilon}\left(1+\eta_{\text {loss }}\right) Q_{\varepsilon}-A_{\text {TPV }} P_{T P V}-A_{\text {rad }} \varepsilon_{\text {rad }} \sigma\left(T_{\text {rad }}^{4}-T_{\text {space }}^{4}\right)=0$

An additional energy balance equation is established at the emitter surface, in order to balance the constant power generation within the GPHS unit:

$A_{e}\left(1+\eta_{\text {loss }}\right) Q_{e}-P_{G P H S}=0$

The expressions for $Q_{e}$ (net radiative energy balance in the emitter) and $p_{T P V}$ (electrical power density of the TPV cells) are obtained following a similar approach than in $[10,99]$, with the main difference of that this time, more general expressions have been obtained in order to consider a photon energy dependent emissivity, i.e. $\varepsilon_{e}(E)$. Two different $Q_{e}$ expressions are obtained for single junction $\left(Q_{e}^{1 J}\right)$ or tandem (dual junction) TPV cells $\left(Q_{e}^{2 J}\right)$ :

$$
\begin{aligned}
& Q_{e}^{1 J}=\pi\left\{F_{e c} \int_{E_{G}}^{\infty} \varepsilon_{e}(E) \dot{e}\left(E, T_{c}, q V\right) d E-\int_{0}^{\infty} \varepsilon_{e}(E) \dot{e}\left(E, T_{e}, 0\right) d E\right. \\
& \left.+\int_{0}^{E_{G}} \frac{A_{e} F_{e c}^{2} \varepsilon_{e}^{2}(E) \rho_{B S R} / A_{T P V}}{1-\rho_{B S R}\left[F_{c c}+\frac{A_{e} F_{e c}^{2}\left(1-\varepsilon_{e}(E)\right)}{A_{T P V}}\right]} \dot{e}\left(E, T_{e}, 0\right) d E\right\} \\
& Q_{e}^{2 J}=\pi\left\{F_{e c}\left(\int_{E_{2}}^{E_{1}} \varepsilon_{e}(E) \dot{e}\left(E, T_{c}, q V_{2}\right) d E+\int_{E_{1}}^{\infty} \varepsilon_{e}(E) \dot{e}\left(E, T_{c}, q V_{1}\right) d E\right)\right. \\
& -\int_{0}^{\infty} \varepsilon_{e}(E) \dot{e}\left(0, \infty, T_{e}, 0\right) d E \\
& \left.+\int_{0}^{E_{2}} \frac{A_{e} F_{e \varepsilon}^{2} \varepsilon_{e}^{2}(E) \rho_{B S R} / A_{T P V}}{1-\rho_{B S R}\left[F_{C C}+\frac{A_{e} F_{e c}^{2}\left(1-\varepsilon_{e}(E)\right)}{A_{T P V}}\right]} \dot{e}\left(E, T_{\varepsilon}, 0\right) d E\right\}
\end{aligned}
$$

where $\dot{e}(E, T, 0)=\left(2 / h^{3} c^{2}\right)\left(\varepsilon^{3} /\left(\exp \left(\frac{(\varepsilon-\mu)}{k T}\right)-1\right)\right)$ is the normal photon energy flux per unit of solid angle of a black body ate temperature $T$. For singlejunction TPV cells, the power density $p_{T P V}$ is the maximum of the function $p(V)=j(V) V$, where

$$
\begin{aligned}
j(V)=q \pi & \int_{E_{G}}^{\infty}\left\{\frac{A_{e} F_{e} \varepsilon_{e}(E)}{A_{T P V}} \dot{n}\left(E, T_{e}, 0\right)-\left(1-F_{C C}\right) \dot{n}\left(E, T_{c}, q V\right) d E\right. \\
& -\left(n^{2}\left(1-\rho_{B S R}\right)+2 n^{2} \gamma_{N R R}\right) \dot{n}\left(E, T_{c}, q V\right) \\
& \left.+\frac{A_{e} F_{e c}^{2}\left(1-\varepsilon_{e}(E)\right)}{A_{T P V}} \dot{n}\left(E, T_{c}, q V\right)\right\} d E
\end{aligned}
$$

where $\dot{n}(E, T, \mu)=\dot{e}(E, T, \mu) / \varepsilon$ is the normal photon flux per unit of solid angle of a black body at temperature $T$. For dual-junction (tandem) TPV cell, the power density $p_{T P V}$ is the maximum of the function $(V)=j_{1}(V) V_{1}+j_{2}(V) V_{2}$, where subscripts " 1 " and " 2 " denote the top-cell and bottom-cell, respectively. In series-interconnected tandem arrangements, an extra condition is $j_{1}(v)=j_{2}(v)$.

$$
\begin{aligned}
j_{1}(v)=q \pi & \int_{E_{1}}^{\infty}\left\{\frac{A_{e} F_{e c} \varepsilon_{e}(E)}{A_{T P V}} \dot{n}\left(E, T_{e}, 0\right)-\left(1-F_{c c}\right) \dot{n}\left(E, T_{c}, q V_{1}\right)\right. \\
& +n^{2}\left(\dot{n}\left(E, T_{c}, q V_{2}\right)-\dot{n}\left(E, T_{c}, q V_{1}\right)\right. \\
& \left.\left.-2 \gamma_{N R R^{\prime}} \dot{n}\left(E, T_{c}, q V_{1}\right)\right)+\frac{A_{e} F_{e c}^{2}\left(1-\varepsilon_{e}(E)\right)}{A_{T P V}} \dot{n}\left(E, T_{c}, q V_{1}\right)\right\} d E
\end{aligned}
$$




$$
\begin{aligned}
j_{2}(v)= & q \pi \int_{E_{2}}^{E_{1}} \frac{A_{e} F_{e c} \varepsilon_{e}(E)}{A_{T P V}} \dot{n}\left(E, T_{e}, 0\right)-\left(1-F_{c c}\right) \dot{n}\left(E, T_{c}, q V_{2}\right) d E \\
& +n^{2} \int_{E_{1}}^{\infty} \dot{n}\left(E, T_{c}, q V_{1}\right)-\dot{n}\left(E, T_{c}, q V_{2}\right) d E \\
& -n^{2} \int_{E_{2}}^{\infty} 2 \gamma_{N R R} \dot{n}\left(E, T_{c}, q V_{2}\right) \\
& +\left(1-\rho_{B S R}\right) \dot{n}\left(E, T_{c}, q V_{2}\right) d E+\int_{E_{2}}^{E_{1}} \frac{A_{e} F_{e c}^{2}\left(1-\varepsilon_{e}(E)\right)}{A_{T P V}} \dot{n}\left(E, T_{c}, q V_{2}\right) d E
\end{aligned}
$$

The meaning of each variable can be found in $[10,99]$. Non-radiative recombination has been taken into account in the above equations by means of the parameter $\gamma_{N R R}=\left(1-\eta_{\text {int }}\right) / \eta_{\text {int }}$, which express the "internal" ratio of non-radiative to radiative recombination (not considering photon recirculation) as a function of the internal photo-luminescence efficiency $\eta_{\text {int }}$. It worth noting that, according to this model, the external photoluminescent efficiency is given as

$\eta_{\text {ext }}=\left(1-n^{2}\left(1+\rho_{B S R}-2 / \eta_{\text {int }}\right)\right)^{-1}$

\section{References}

[1] A. Luque, S. Hegedus, Handbook of Photovoltaic Science and Engineering, Wiley, UK, 2003.

[2] K. Stephenson, T. Blancquaert, Nuclear power technologies for deep space and planetary missions, Presented at in: Proceedings of the 8th European Space Power Conference, Constance, Germany, 2008.

[3] D. Anderson, W. Wong, and K. Tuttle, An overview and status of nasa's radioisotope power conversion technology NRA, in: Proceedings of the 3rd International Energy Conversion Engineering Conference, American Institute of Aeronautics and Astronautics.

[4] R.G. Lange, W.P. Carroll, Review of recent advances of radioisotope power systems, Energy Convers. Manag. 49 (3) (2008) 393-401.

[5] R. L. Cataldo, G. Bennett, U.S. Space Radioisotope Power Systems and Applications: Past, Present and Future, 2011.

[6] T. Bauer, Thermophotovoltaics: basic Principles and Critiical Aspects of System Design, Springer, Heidelberg, 2011.

[7] D.L. Chubb, Fundamentals of thermophotovoltaic energy conversion, Elsevier, The Netherlands, 2007.

[8] T.J. Coutts, A review of progress in thermophotovoltaic generation of electricity, Renew. Suitable Energy Rev. 3 (1999) 77-184.

[9] B. Wernsman, R.R. Siergiej, S.D. Link, R.G. Mahorter, M.N. Palmisiano, R.J. Wehrer, R.W. Schultz, G.P. Schmuck, R.L. Messham, S. Murray, C.S. Murray, F. Newman, D. Taylor, D.M. DePoy, T. Rahmlow, Greater than $20 \%$ radiant heat conversion efficiency of a thermophotovoltaic radiator/module system using reflective spectral control, IEEE Trans. Electron Devices 51 (3) (2004) 512-515.

[10] A. Datas, Optimum semiconductor bandgaps in single junction and multijunction thermophotovoltaic converters, Sol. Energy Mater. Sol. Cells 134 (2015) 275-290.

[11] F. A. Vicente, C. E. Kelly, S. Loughin, Thermophotovoltaic (TPV) applications to space power generation, in: Proceedings of the Energy Conversion Engineering Conference, IECEC 96, Proceedings of the 31st Intersociety, 1996, vol. 1, pp. 635640 .

[12] D. Wilt, D. Chubb, D. Wolford, P. Magari, C. Crowley, Thermophotovoltaics for Space Power Applications, in: Proceedings of the AIP Conference, vol. 890, 2007 pp. 335-345.

[13] V. L. Teofilo, P. Choong, W. Chen, J. Chang, Y. L. Tseng, Thermophotovoltaic energy conversion for space applications,Space Technology and Applications International Forum - STAIF, vol. 813, 2006, pp. 552-559.

[14] V.L. Teofilo, P. Choong, J. Chang, Y.-L. Tseng, S. Ermer, Thermophotovoltaic energy conversion for space†,, J. Phys. Chem. C 112 (21) (2008) 7841-7845.

[15] A. L. Presby, Thermophotovoltaic energy conversion in space nuclear reactor power systems, Thesis, Monterey California. Naval Postgraduate School, 2004.

[16] L. S. Mason, M. A. Gibson, D. Poston, Kilowatt-Class Fission Power Systems for Science and Human Precursor Missions, 2013.

[17] M. A. Gibson, L. S. Mason, C. L. Bowman, D. I. Poston, P. R. McClure, J. Creasy, C. Robinson, Development of NASA's Small Fission Power System for Science and Human Exploration, 2015.

[18] D.M. Rowe, Thermoelectrics Handbook: Macro to Nano, CRC Press, 2005.

[19] R.K. Shaltens, Future Opportunities for Dynamic Power Systems for NASA Missions presented at the International Stirling Forum 2006, Osnabruck Germany, 2007.

[20] NASA, NASA Technology Roadmaps. TA 3: Space Power and Energy Storage, 2015.

[21] G.N. Hatsopoulos, E.P. Gyftopoulos, Thermionic Energy Conversion 2, The MIT Press, Cambridge, Mascachusetts, 1979.

[22] Thermionics Quo Vadis?, An Assessment of the DTRA's Advanced Thermionics Research and Development Program, National Academies Press, Washington, D.C, 2001.

[23] G. Miskolczy, D.P. Lieb, Radioisotope Thermionic Converters for Space Applications, in: Proceedings of the Energy Conversion Engineering Conference, IECEC-90, Proceedings of the 25th Intersociety, 1990, vol. 1, pp. 222-226.

[24] R.T. Lahey, V. Dhir, Research in Support of the Use of Rankine Cycle Energy
Conversion Systems for Space Power and Propulsion, 2004.

[25] G. L.Yoder, Technology Development Program for an Advanced Potassium Rankine Power Conversion System Compatible with Several Space Reactor Designs, ORNL/ TM-2004/214, 2005.

[26] L.S. Mason, J.G. Schreiber, A Historical Review of Brayton and Stirling Power Conversion Technologies for Space Applications, 2007.

[27] L.S. Mason, A Summary of Closed Brayton Cycle Development Activities at NASA, 29- Apr-2009.

[28] C.A. Hall, E.K. Glakpe, J.N.Cannon, T.W. Kerslake, Modeling Cyclic Phase Change and Energy Storage in Solar Heat Receivers, presented at the Thermodynamics, 2325 Jun. 1997, United States, 1997.

[29] R.L. Fuller, Closed Brayton Cycle Power Conversion Unit for Fission Surface Power Phase I Final Report, Jun. 2010.

[30] M. Briggs, M. Gibson, S. Geng, J. Pearson, T. Godfroy, Development Status of the Fission Power System Technology Demonstration Unit, 2012.

[31] S.M. Oriti, Advanced Stirling Radioisotope Generator Engineering Unit 2 (ASRG EU2) Final Assembly, presented at the Nuclear and Emerging Technologies for Space 2015, Albuquerque, NM, United States, 2015.

[32] NASA, Advanced Stirling Radioisotope Generator (ASRG), NF-2013-07-568-HQ.

[33] S.Wilson, Overview of stirling technology research at NASA glenn research center, in: Proceedings of the 13th International Energy Conversion Engineering Conference, American Institute of Aeronautics and Astronautics, 2015.

[34] A. Schock, C.T. Or, V. Kumar, Modified design of radioisotope thermophotovoltaic generator to mitigate adverse effect of measured cell voltage, in: Proceedings of the Energy Conversion Engineering Conference IECEC 96, Proceedings of the 31st Intersociety, vol. 2, 1996, pp. 979-986.

[35] C.S. Murray, C.J. Crowley, S. Murray, N.A. Elkouh, R.W. Hill, D. E.Chubb, Thermophotovoltaic Converter Design for Radioisotope Power Systems, in: Proceedings of the AIP Conference, vol. 738, 2004, pp. 123-132.

[36] C.J. Crowley, N.A. Elkouh, S. Murray, D. L. Chubb, Thermophotovoltaic converter performance for radioisotope power systems, in: Proceedings of the AIP Conference, vol. 746, 2005, pp. 601-614.

[37] D. Wolford, D.L. Chubb, Theoretical performance of a radioisotope thermophotovoltaic (RTPV) power system, presented at in: Proceedings of the 7th International Energy Conversion Engineering Conference, Denver, Colorado, 2009.

[38] D. Wilt, R. Wehrer, M. Palmisiano, M. Wanlass, C. Murray, Monolithic interconnected modules (MIMs) for thermophotovoltaic energy conversion, Semicond. Sci. Technol. 18 (5) (2003) (p. PII S0268-1242(03)(60134-3).

[39] L.S. Mason, Realistic specific power expectations for advanced radioisotope power systems, J. Propuls. Power 23 (5) (2007) 1075-1079.

[40] J. Strauch, A. Klein, P. Charles, C. Murray, M. Du, Radioisotope fueled thermophotovoltaic power systems for space applications, in: Proceedings of Nuclear \& Emerging Technologies for Space (NETS), 2015, p. 5145.

[41] N.-P. Harder, P. Würfel, Theoretical limits of thermophotovoltaic solar energy conversion, Semicond. Sci. Technol. 18 (2003) S151-S157.

[42] A. Datas, C. Algora, Global optimization of solar thermophotovoltaic systems, Prog. Photovolt:: Res. Appl. (2012) (vol. Published Online).

[43] A. Datas, Development of Solar Thermophotovoltaic Systems, Universidad Politécnica de Madrid, Madrid, Spain, 2011.

[44] A. Lenert, D.M. Bierman, Y. Nam, W.R. Chan, I. Celanovic, M. Soljacic, E.N. Wang, A nanophotonic solar thermophotovoltaic device, Nat. Nano 9 (2) (2014) 126-130.

[45] Z. Zhou, E. Sakr, Y. Sun, P. Bermel, Solar thermophotovoltaics: reshaping the solar spectrum, Nanophotonics $0(0)(2016)$.

[46] D.L. Chubb, B.S. Good, R.A. Lowe, Solar thermophotovoltaic (STPV) system with thermal energy storage, 1995 , pp. 181-198.

[47] A. Datas, D.L. Chubb, A. Veeraragavan, Steady state analysis of a storage integrated solar thermophotovoltaic (SISTPV) system, Sol. Energy 96 (2013) 33-45.

[48] A. Veeraragavan, L. Montgomery, A. Datas, Night time performance of a storage integrated solar thermophotovoltaic (SISTPV) system, Sol. Energy 108 (0) (2014) $377-389$.

[49] A. Datas, A. Ramos, A. Martí, C. del Cañizo, A. Luque, Ultra high temperature latent heat energy storage and thermophotovoltaic energy conversion, Energy 107 (2016) 
542-549.

[50] D. Namkoong, D. Jacqmin, A.Szaniszlo, Effect of microgravity on material undergoing melting and freezing: The TES Experiment, Presented at the Aerospace Sciences Meeting and Exhibit, 9-12 Jan. 1995, United States, 1995.

[51] M.R. Gilpin, D.B.Scharfe, M.P. Young, A.P. Pancotti, Molten boron phase-change thermal energy storage to augment solar thermal propulsion systems, presented at in: Proceedings of the 47th AIAA Joint Propulsion Conference, San Diego, CA (US), 2011.

[52] M.R. Gilpin, D.B. Scharfe, M.P. Young, Phase-change thermal energy storage and conversion: development and analysis for solar thermal propulsion, presented at in: Proceedings of the 48th AIAA/ASME/SAE/ASEE Joint Propulsion Conference \& Exhibit, Atlanta, GE (US), 2012.

[53] M.R. Reid, D.B. Scharfe, R.N. Webb, Computational evaluation of a latent heat energy storage system, Sol. Energy 95 (2013) 99-105.

[54] M.R. Gilpin, High temperature latent heat thermal energy storage to augment solar thermal propulsion for microsatellites, University of Southern California, 2015

[55] T.R. Amundson, K.M. Webb, R.N. Webb, Numerical power output predictions for low-bandgap thermophotovoltaic cells coupled with a latent-heat energy storage system, J. Energy Storage 6 (2016) 204-212.

[56] E. Marsch, R. Marsden, R. Harrison, R. Wimmer-Schweingruber, B. Fleck, Solar orbiter-mission profile, main goals and present status, Adv. Space Res. 36 (8) (2005) 1360-1366.

[57] J. van Casteren, M. Novara, BepiColombo mission, Memorie della Societa Astronomica Italiana 82 (2011) 394.

[58] Solar Probe Plus: Report of the Science and Technology Definition Team, NASA/ TM-2008-214161, 2008.

[59] K.W. Stone E.F. Leingang S.M. Kusek -On-sun test results of McDonnell Douglas' prototype solar thermophotovoltaic power system, 1994, pp. 2010-2013.

[60] E. Horne, Hybrid Thermophotovoltaic Power Systems, EDTEK, Inc., 2002

[61] A. Datas, C. Algora, Development and experimental evaluation of a complete solar thermophotovoltaic system, Prog. Photovolt: Res. Appl. (2012) (vol. Published Online).

[62] C. Ungaro, S.K. Gray, M.C. Gupta, Solar thermophotovoltaic system using nanostructures, Opt. Express 23 (19) (2015) A1149.

[63] D.M. Bierman, A. Lenert, W.R. Chan, B. Bhatia, I. Celanović, M. Soljačić, E.N. Wang, Enhanced photovoltaic energy conversion using thermally based spectral shaping, Nat. Energy 1 (6) (2016) 16068.

[64] P.M. Fourspring, D.M. DePoy, J.F. Beausang, E.J. Gratrix, R.T. Kristensen, T.D.R. Jr, P.J. Talamo, J.E. Lazo-Wasem, B.Wernsman, Thermophotovoltaic spectral control, in: Proceedings of the AIP Conference, vol. 738, 2004, pp. 171-179.

[65] Y.X. Yeng, W.R. Chan, V. Rinnerbauer, J.D. Joannopoulos, M. Soljačić, I. Celanovic, Performance analysis of experimentally viable photonic crystal enhanced thermophotovoltaic systems, Opt. Express 21 (S6) (2013) A1035-A1051.

[66] K.A. Arpin, M.D. Losego, A.N. Cloud, H. Ning, J. Mallek, N.P. Sergeant, L. Zhu, Z. Yu, B. Kalanyan, G.N. Parsons, G.S. Girolami, J.R. Abelson, S. Fan, P.V. Braun, Three-dimensional self-assembled photonic crystals with high temperature stability for thermal emission modification, Nat. Commun. 4 (2013), 2013.

[67] P. Nagpal, D.P. Josephson, N.R. Denny, J. DeWilde, D.J. Norris, A. Stein, Fabrication of carbon/refractory metal nanocomposites as thermally stable metallic photonic crystals,, J. Mater. Chem. 21 (29) (2011) 10836-10843.

[68] M.W. Dashiell, J.F. Beausang, H. Ehsani, G.J. Nichols, D.M. DePoy, L.R. Danielson, P. Talamo, K.D. Rahner, E.J. Brown, S.R. Burger, P.M. Fourspring, W.F. Topper, P.F. Baldasaro, C.A. Wang, R.K. Huang, M.K. Connors, G.W. Turner, Z.A. Shellenbarger, G. Taylor, J. Li, R. Martinelli, D. Donetski, S. Anikeev, G.L. Belenky, S. Luryi, Quaternary InGaAsSb thermophotovoltaic diodes, Electron Devices, IEEE Trans. on 53 (12) (2006) 2879-2891.

[69] R. Wehrer, M. Wanlass, D. Wilt, B. Wernsman, R. Siergiej, J. Carapella, InGaAs series-connected, tandem, MIM TPV converters, in: Proceedings of the 3rd World Conference on Photovoltaic Energy Conversion, 2003, vol. 1, pp. 892-895.

[70] R. Siergiej, S. Sinharoy, R.J. Valko, R.J. Wherer, B. Wernsman, R.W. Link, S.D. Schultz, R.L. Messham, InGaAsP/InGaAs tandem TPV device, in: Procedings of the AIP Conference, Freiburg, Germany, vol. 738, 2004, p. 480.

[71] R.J. Wehrer, M.W. Wanlass, B. Wernsman, J.J. Carapella, S.P. Ahrenkiel, D.M. Wilt, and C.S. Murray, 0.74/0.55-eV Ga(x) $\ln (1-x) A s / \ln A s(y) P(1-y)$ monolithic, tandem, MIM TPV converters: Design, growth, processing and performance, 2002.

[72] M.G. Mauk, V.M. Andreev, GaSb-related materials for TPV cells, Semicond. Sci. Technol. 18 (5) (2003) S191.

[73] O.V. Sulima, A.W. Bett, P.S. Dutta, M.G. Mauk, R. L. Mueller, GaSb-, InGaAsSb-, InGaSb-, InAsSbP- and Ge-TPV cells with diffused emitters, in: Proceedings of the Photovoltaic Specialists Conference, 2002. Conference Record of the Twenty-Ninth
IEEE, 2002, pp. 892-895.

[74] M.G. Mauk, O.V. Sulima, J.A. Cox, R.L. Mueller, Low-bandgap ( 0.3 to $0.5 \mathrm{eV}$ ) InAsSbP thermophotovoltaics: assessment for open-circuit voltage improvements, in: Proceedings of the 3rd World Conference on Photovoltaic Energy Conversion, 2003, vol. 1, p.224-227.

[75] A. Krier, M. Yin, A.R.J. Marshall, S.E. Krier, Low bandgap inas-based thermophotovoltaic cells for heat-electricity conversion, J. Electron. Mater. 45 (6) (2016) 2826-2830.

[76] V.A. Gevorkyan, V.M. Aroutiounian, K.M. Gambaryan, I.A. Andreev, L.V. Golubev, Y.P. Yakovlev, InAsSbP/InAs heterostructures for thermophotovoltaic converters: growth technology and properties, Tech. Phys. Lett. 34 (1) (2011) 69-71.

[77] Young-Waithe, K, A. Karen, Process design, development and fabrication of InAs homojunction converter cells for microscale thermophotovoltaic application (S.M Thesis), Massachusetts Institute of Technology, 2000.

[78] J.P. Connolly, C. Rohr, Quantum well cells for thermophotovoltaics, Semicond. Sci. Technol. 18 (5) (2003) S216.

[79] G.E. Cragg, A.L. Efros, Suppression of auger processes in confined structures, Nano Lett. 10 (1) (2010) 313-317.

[80] I. Ramiro, A. Marti, E. Antolin, A. Luque, Review of experimental results related to the operation of intermediate band solar cells, IEEE J. Photovolt. 4 (2) (2014) $736-748$.

[81] M.C. Beard, J.M. Luther, A.J. Nozik, The promise and challenge of nanostructured solar cells, Nat. Nano 9 (12) (2014) 951-954.

[82] J. Yin, R. Paiella, Multiple-junction quantum cascade photodetectors for thermophotovoltaic energy conversion, Opt. Express 18 (2) (2010) 1618.

[83] S. Basu, Y.-B. Chen, Z.M. Zhang, Microscale radiation in thermophotovoltaic devices-A review, Int. J. Energy Res. 31 (6-7) (2007) 689-716.

[84] K. Park, S. Basu, W.P. Kingb, Z.M. Zhang, Performance analysis of near-field thermophotovoltaic devices considering absorption distribution, J. Quant. Spectrose. Radiat. Transf. 209 (2) (2008) 305-316.

[85] M.P. Bernardi, O. Dupré, E. Blandre, P.-O. Chapuis, R. Vaillon, M. Francoeur, Impacts of propagating, frustrated and surface modes on radiative, electrical and thermal losses in nanoscale-gap thermophotovoltaic power generators, Sci. Rep. 5 (2015) 11626.

[86] M. Francoeur, R. Vaillon, M.P. Mengüc, Thermal impacts on the performance of nanoscale-gap thermophotovoltaic power generators, Energy Convers. IEEE Trans. 6 (2) (2011) 686-698.

[87] R. Messina, P. Ben-Abdallah, Graphene-based photovoltaic cells for near-field thermal energy conversion, Sci. Rep. 3 (2013).

[88] S. Molesky, Z. Jacob, Ideal near-field thermophotovoltaic cells, Phys. Rev. B 91 (20) (2015).

[89] R.S. DiMatteo, P. Greiff, S.L. Finberg, K.A. Young-Waithe, H.K.H. Choy, M.M. Masaki, C. G. Fonstad, Micron-gap ThermoPhotoVoltaics (MTPV), in: Proceedings of the AIP Conference ,vol. 653, 1, 2003, pp. 232-240.

[90] K. Hanamura, K. Mori, Nano-gap TPV Generation of Electricity through Evanescent Wave in Near-field Above Emitter Surface, in: Proceedings of the AIP Conference, vol. 890, 1, 2007, pp. 291-296.

[91] K. Ito, A. Miura, H. Iizuka, H. Toshiyoshi, Parallel-plate submicron gap formed by micromachined low-density pillars for near-field radiative heat transfer, Appl. Phys. Lett. 106 (8) (2015) 83504.

[92] N.-P. Harder, M.A. Green, Thermophotonics, Semicond. Sci. Technol. 18 (5) (2003) S270.

[93] K.L. Lin, K.R. Catchpole, P. Campbell, M.A. Green, High external quantum efficiency from double heterostructure InGaP/GaAs layers as selective emitters for thermophotonic systems, Semicond. Sci. Technol. 19 (11) (2004) 1268.

[94] J. Oksanen, J. Tulkki, Thermophotonic heat pump-a theoretical model and numerical simulations, J. Appl. Phys. 107 (9) (2010) 93106.

[95] D.J. Farrell, H. Sodabanlu, Y. Wang, M. Sugiyama, Y. Okada, A hot-electron thermophotonic solar cell demonstrated by thermal up-conversion of sub-bandgap photons, Nat. Commun. 6 (2015).

[96] M. K. Goldstein, L.G. DeShazer, A. S. Kushch, S.M. Skinner, Superemissive light pipe for TPV applications, in: Proceedings of the AIP Conference, vol. 401, 1997, pp. $315-326$.

[97] D.L. Chubb, Light Pipe Thermophotovoltaics (LTPV), presented at the Thermophotovoltaic Generation of Electricity: TPV7, vol. 890, 2007, pp. 297-316.

[98] A. Datas, Hybrid thermionic-photovoltaic converter, Appl. Phys. Lett. 108 (14) (2016) 143503.

[99] A. Datas, C. Algora, Detailed balance analysis of solar thermophotovoltaic systems made up of single junction photovoltaic cells and broadband thermal emitters, Sol Energy Mater. Sol. Cells 94 (12) (2010) 2137-2147. 